\title{
CONSTRUCTING THE DIFFUSION-LIKE MODEL OF BICOMPONENT KNOWLEDGE POTENTIAL DISTRIBUTION
}

\author{
Andrii Bomba ${ }^{1)}$, Mariia Nazaruk ${ }^{2)}$, Natalia Kunanets ${ }^{2)}$, Volodymyr Pasichnyk ${ }^{2)}$ \\ ${ }^{1)}$ Rivne State Humanitarian University, 12 S. Bandery str., Rivne, 33000, Ukraine, abomba@ukr.net \\ ${ }^{2)}$ Lviv Polytechnic National University, 12 S. Bandery str., Lviv, 79000, Ukraine, marinazaruk@gmail.com
}

\begin{abstract}
The concept of knowledge potential of agents which serves as a characteristic of a certain amount of knowledge of any individual accumulated over a certain period of life is presented in the paper. The original model approach to information processes of knowledge potential dissemination based on physical analogies, namely the phenomenon of diffusion, is proposed. The redistribution process of two-component knowledge potential is described and the results of numerical experiments are given. The diffusion-like models of knowledge potential distribution in the social and communicative educational environment of the city are built. In particular, the attention is focused on the description (modeling) of knowledge potential redistribution processes within a given social and communicative community (clique), with well-established external and internal relationship between the members (agents) of educational and training processes. Solutions to the modeling problem of interaction (interference) between the knowledge potential components of different agents within a given clique are proposed, a multi-vector of knowledge potential is considered and the results of numerical experiments are given. Copyright (C) Research Institute for Intelligent Computer Systems, 2017. All rights reserved.
\end{abstract}

Keywords: educational environment of a city, agent, clique, knowledge potential, diffusion-like model.

\section{INTRODUCTION}

The educational environment of a modern city is created in the system of information flows (knowledge potential flows). Its functions are implemented within this system where, in particular, the processes of knowledge creating, learning and transferring from one group of individuals to others are occurring with the use of computer networks and systems of information and social and communicative technologies.

In general, a wide range of educational processes occurring in the social and communicative environment of a big city conceptually fit into a generalized methodological representation of conceptual and terminological triad "Information Data - Knowledge". It is suggested giving an additional characteristic for the concept of "knowledge" by which it is fixed the certain knowledge level of a person which is served as a characteristic of certain totality, the knowledge amount of an individual accumulated over the appropriate life period. It is proposed to mark this characteristic as a "knowledge potential" $-\varphi$. Knowledge potential can be both a real entity and a virtual one - library, informational Internet resource, etc.
The change of knowledge potential $\varphi$ allows individuals of the social and communicative educational environment of a city (the pupils of kindergarten, primary school students, high school students, Bachelor's or Master's degree students etc.) to move to another level of education or qualification.

When the educational environment is considered as an integrated system, information processing of knowledge has primary importance for this system. Also, knowledge is one of the most significant and meaningful resources of learning and educational environment in the "smart cities". Currently, various forms and means of knowledge representation, organization of educational and learning activities and communications are spreading as well as many areas of system development, based on knowledge are appearing [1].

Nowadays, there is an increasing amount of scientific works devoted to the analysis and the research of knowledge management [2, 3] and related processes of organization, gathering, transformation, dissemination and usage aimed at providing the effective functioning of a big city [46].

Nonaka Ikujiro offers a system to describe the dynamic process of knowledge creating, where 
knowledge is created through a synthesis of thinking and actions of individuals who interact with each other inside and outside the organizational boundaries $[7,8]$.

In the works $[9,10]$ the mathematical models of knowledge spreading and learning management of students are built, and the hybrid agent-based models of knowledge evaluating of distance learning participants by using the artificial neural networks are developed.

In the works of scientists the probabilistic and statistical approach to analytical modeling of educational process was developed. The comprehension or forgetting the knowledge unit is regarded as a random event, but learning is characterized by parameters functionally related to the time. In more general terms, stochastic learning process by its nature is regarded as semi-Markovian, in which the probability of transition from one state to another depends on both the initial state and the state in which the transition is accomplished [11]. Taking into account the nature of learning, it is assumed that only transitions to neighboring states, which depend on time, can be possible. As a result the system of differential equations with timedependent coefficients, which do not always have analytical solutions, is received.

The models of diffusion information distribution in social and communicative areas using mathematical tools of cellular automata were developed [12].

Knowledge is a product that is produced due to the peculiarities of technological process, the demands of society, the market and scientific conditions. A network model of learning process is described in works [14-16] using Rogers "diffusion of innovations" [13]. Such a description is useful because it allows optimizing the innovation process adjusting the starting stimulus. However, the revolutionary solutions within such models cannot be found.

The Bass model [17] is used for the analysis of the diffusion characteristics of knowledge transmissions, which allows distinguishing the adaptive and imitating diffusional characteristics and quasistationary rods [18].

The analysis of scientific works allows concluding that the proposed models do not provide an opportunity to consider a number of unknown variables that affect the outcome. Firstly, it is a characteristic group of agents, including features that determine the rate of intra dissemination of knowledge. Secondly, the model does not describe the transition of knowledge from one group to another: the question is remained open about the extent of boundary between the groups if it is a contact or barrier zone.
The adaptive characteristics of educational objects have not been revealed and models of knowledge potential transition from some subjects of the educational environment to others have not been shown in the existing studies as each author considers only his own separate aspect.

We propose to use mathematical device that is designed for natural phenomena and processes of the material world for description of the knowledge potential dissemination between the subjects of the educational social and communicative environment. This is due to the fact that it is a clear analogy between the process of knowledge dissemination and melt crystallization of solids by heating.

As a logical consequence of such an interpretation of the concept of knowledge potential spread is an attempt to describe these processes as an appropriate diffusion-like model.

Traditionally, the diffusion processes under the conditions of convection and mass transfer (presence of internal sources) are described by the following differential equation:

$$
\begin{aligned}
& \varphi_{t}=D\left(\varphi_{x x}+\varphi_{y y}+\varphi_{z z}\right)-\left(v_{x} \varphi_{x}+v_{y} \varphi_{y}+v_{z} \varphi_{z}\right)+ \\
& +f\left(x, y, z, t, \varphi, \alpha_{1}, \alpha_{1}, \ldots, \beta_{1}, \beta_{2}, \ldots\right)
\end{aligned}
$$

where $\varphi-$ the concentration of substance that is involved in modeling, $D$ - diffusivity, $t$ - time, $x, y, z$ - spatial coordinates, $v_{x}, v_{y}, v_{z}$ - convective transfer speed, $f$ - the defined function that describes the intensity of internal sources (pollution, heat, radiation, etc., depending on the subject area), $\alpha, \beta$ - parameters that characterize "internal identities" and external factors.

The task of the paper is to build a mathematical diffusion-like model of redistribution of twocomponent knowledge potential $\varphi$ in the social and communicative environment of a big city based on replenishment of knowledge of an agent.

\section{MATHEMATICAL DIFFUSION-LIKE MODELS OF DISTRIBUTION OF KNOWLEDGE POTENTIAL}

It is proposed to present the educational social and communicative environment of a big city in the paper [19] as a network graph $G=(A, R)$, where $A=\left\{a_{1}, a_{2}, \ldots, a_{n}\right\}-$ is not empty finite set of nodes (agents), $R=\left\{r_{1}, r_{2}, \ldots, r_{k}\right\}-$ is a set of unordered pairs of different elements from $A$ (the ratio between agents).

The agents in this case are understood as pupils, students, postgraduate students and others who study 
as well as teachers, educators, teaching staff, librarians, parents, businesses, institutions, companies, corporations, non-governmental organizations of a big city participating in educational and learning processes.

In addition, the relationship between agents may particularly be interpreted as "friendship", "cooperation", "communication", "education" and other forms of interaction that are immanent to entities of the educational social and communication environment of a city.

Agents within a certain educational level can be united by common attributes and characteristics (e.g., age, education level, training in one institution), and form the so-called clique (social communities) $K_{j},(j=\overline{1, n})$ - subgraphs or classes for which connections between nodes within such class or group are stronger and more numerous than between nodes of other classes or groups according to subgraphs.

The formation of the corresponding cliques (groups, associations, classes) in the educational social and communicative environment of a big city in many cases can occur with an active involvement of modern mobile telecommunications. In turn, it technically provides processes of structuring of the virtual educational social and communicative environment minimizing the impact of such factors as a physical distance between participants of the educational process, the age and the special educational needs of a certain individual.

The main unifying factor in the formation and functioning of this educational social group is a need to improve knowledge potential $\varphi$ of its participants for a particular profile and level.

Diffusion process of knowledge potential spread between agents within a certain clique $K_{j}$, in the paper [20] is proposed to be presented as the following:

$$
\begin{aligned}
& \varphi_{j, k, m+1}=\varphi_{j, k, m}+f_{j, k, m}+D_{j, k, m} \sum_{1 \leq \underline{k}<k<\bar{k} \leq k_{j}} \sigma_{k, \underline{k}, \bar{k}} * \\
& *\left(\varphi_{j, \bar{k}, m}-2 \varphi_{j, k, m}+\varphi_{j, \underline{k}, m}\right) \\
& 1 \leq \underline{k}<k<\bar{k} \leq k_{j}, \bar{k} \neq \underline{k}
\end{aligned}
$$

where $\varphi_{j, k, m}-$ a numerical characteristic of knowledge potential of $k$ agent in $j$ educational group $a_{j k}\left(j=\overline{1, k}, k=\overline{1, k_{j}}\right)$ at some time $t=t_{m}$ ( $\left.m=0,1,2, \ldots, ; t_{m}=\Delta t m\right)$, where $\Delta t-$ a time interval at time $m, D_{j, k, m}-$ coefficient that characterizes the ability of $k$ agent in $j$ educational group to redistribute the information (knowledge) at time $m$ (analogue of diffusion coefficient), $f_{j, k, m}$ - a numerical characteristic of the main information sources (knowledge), $\sigma_{k, k, \bar{k}}$ some weights coefficients. Note that the source of information may be one or more of the selected agents of a social and communicative community, for example $f_{j, k, m}=\gamma_{m} \varphi_{j, k, m}, \quad$ where $k=\overline{k_{1}}, \overline{k_{2}}, \ldots, \overline{k_{j}}, 1<\overline{k_{1}}<\overline{k_{2}}<\ldots<\overline{k_{j}}<k_{j}$ (if clique within a school educational level is an association of students of a particular profile class, their teacher will be as a source of "knowledge").

There are different possible options to install the ways (methods) of information redistribution (knowledge) between agents belonging to one social community (clique), agent groups of various clicks and between clicks within a certain educational level and the educational social and communicative environment of a city in general (it should be introduced an additional index that would correspond to a particular level of education).

In the above models, we operated with some abstract (too average) potential $\varphi$.

\subsection{SUMMARIZING THE MATHEMATICAL MODEL OF KNOWLEDGE POTENTIAL SPREADING}

We denote $\varphi_{k, m}$ as a knowledge potential of $k$ agent in $m$ time, and $\alpha_{k, i, m}-$ as a "bandwidth" (coefficient of perception) by $i$ agent of $k$ (for easy exposition, we believe that $\alpha_{k, i, m}=\alpha_{k, i}$, it means that the nature of perception or transmission of information between $k$ and $i$ agents doesn't depend on time). Then the law of redistribution of knowledge potential is presented in the form:

$$
\begin{aligned}
& \varphi_{k, m+1}-\varphi_{k, m}=\alpha_{k, 1}\left(-\varphi_{k, m}+\varphi_{1, m}\right)+\ldots+ \\
& +\alpha_{k, k_{j}}\left(-\varphi_{k, m}+\varphi_{k_{j}, m}\right) \\
& \varphi_{k, m+1}=\varphi_{k, m}+\sum_{i=1}^{k_{j}} \alpha_{k, i}\left(\varphi_{k, m}-\varphi_{k, i}\right)
\end{aligned}
$$

In particular, if interaction takes place only between adjacent objects (placed in a row), when only "surrounding" ones $\alpha_{k, i}=\alpha_{k-1, i}=\alpha_{k+1, i}=\alpha$ are different from zero, then (1) is analogous to the difference schemes for differential equations:

$$
U_{t}=\alpha^{2} U_{x x}
$$

where $t$-time, $x$ - spatial variable. 


$$
\begin{aligned}
& U_{k, m+1}-U_{k, m}=\alpha^{2}\left(U_{k+1, m}-2 U_{k, m}+U_{k, m+1}\right) \\
& \alpha=\frac{\Delta t \alpha^{2}}{(\Delta x)^{2}}
\end{aligned}
$$

It is believed that the following initial distribution of knowledge potential is well-known:

$$
\varphi_{k, 0}=\vartheta_{k}, \quad k=\overline{1, k_{j}}
$$

and the nature of change in time of "extreme" objects, such as:

$$
\begin{array}{ll}
\varphi_{1, m}=\vartheta_{*_{m}}, & \varphi_{k_{j}, m}=\vartheta_{m}^{*}, \quad m=0,1,2, \ldots, \\
\left(\vartheta_{*_{0}}=\vartheta_{0},\right. & \left.\vartheta_{0}^{*}=\vartheta_{k_{j}}\right)
\end{array}
$$

So, in the next moments the corresponding situational conditions are being characterized by formulas (3-5). Thus, it is clear that the peculiarity of $k$ agent according to (3) with respect to $\left(3^{*}\right)$ in the process of transition to $(m+1)$ state, is an "involvement" of all objects of $m$ state (but not only surrounding ones, that takes place according to $(3 *))$.

It is noticed that the drawback of this model is the lack of information sources; its potential is not reduced due to its transfer to different individuals. Indeed, in the discussed above case, individuals (objects) that have high information capacity at the beginning of the process become "stupid" over time (in fact, their information potential spreads and becomes equal to that one of other individuals). Note, a similar phenomenon is observed, for example, in finding solutions to simple diffusion equation (without constant term) $U_{t}=\alpha^{2} U_{x x}$.

In case of information source (teacher), whose potential is not reduced, the equation (3) is summarized like this:

$$
\varphi_{k, m+1}=\varphi_{k, m}+\sum_{i=1}^{k_{j}} \alpha_{k, i}\left(\varphi_{k, m}-\varphi_{k, i}\right)+f_{m}
$$

where, $f_{m}$ - intensity of information sources in $m$ time (it means that the information source in this case influences on all objects similarly). Of course, more complicated cases can be considered where the "teacher" fills the knowledge potentials of various individuals differently, then instead of $f_{m}$ we will have $f_{k, m}$ (even $\left.f_{k, i, m}\right)$.

The disadvantage of this model is that each item (clique) is characterized by only one potential. But, of course (in reality), for example, students are characterized with different potentials (e.g., knowledge of mathematics, history, etc.).

\subsection{MODEL SUMMARY IN CASE FOR DETERMINATION OF VECTOR POTENTIALS}

We will consider the case where each $(k)$ of objects (cliques, agents) is characterized by two potentials. Namely, $\varphi_{l, k, m}$ is denoted as $l$ potential ( $l=1,2$, e.g. potentials characterizing knowledge of mathematics and language) of $k$ agent in $m$ time. Then, the model that describes the redistribution of potentials with possible consideration of "influence" one of them on another (such as obtaining a high mathematical potential may affect speech one - for the object, or vice versa, there can be positive mutual influences) can be represented as:

$$
\left\{\begin{array}{c}
\varphi_{1, k, m+1}=\varphi_{1, k, m}+\sum_{i=1}^{k_{j}} \alpha_{1, k, i}\left(f_{1, k, m}+g_{1, m}\left(\varphi_{1, k, k}\right)+\right. \\
\left.\varphi_{2, k, m+1}=\varphi_{2, k, m}\right) \\
k_{2, k, m}+\sum_{i=1}^{k_{j}} \alpha_{2, k, i}\left(\varphi_{2, k, m}-\varphi_{2, k, i}\right)+ \\
g_{2, m}\left(\varphi_{1, k, m}, \varphi_{2, k, m}\right)
\end{array}\right.
$$

where, $f_{1, m}, f_{2, m}$ - intensity source of knowledge transfer, for example, with the help of mathematics and language teachers, $g_{1, m}\left(\varphi_{1, k, m}, \varphi_{2, k, m}\right)$, $g_{2, m}\left(\varphi_{1, k, m}, \varphi_{2, k, m}\right)$ - functions that characterize interdependence (mutual influence) between studying mathematics and language in this case. For example, if $\quad g_{1, m}\left(\varphi_{1, k, m}, \varphi_{2, k, m}\right) \quad$ and $g_{2, m}\left(\varphi_{1, k, m}, \varphi_{2, k, m}\right)$ are equal $\alpha_{1} \varphi_{1, k, m}-\beta_{1} \varphi_{2, k, m}$, $-\alpha_{2} \varphi_{1, k, m}+\beta_{2} \varphi_{2, k, m}$, where $\alpha_{1} \alpha_{2}, \beta_{1}, \beta_{2}$ - positive real numbers, we have a case when language learning negatively affects the knowledge of mathematics and vice versa. If we consider the last two expressions with "pluses", the case will have a positive impact of studying one of these subjects to others.

If the objects (agents) are characterized by many potentials when $l=1,2, \ldots, l_{*}$ we will have:

$\left\{\begin{array}{c}\varphi_{l, k, m+1}=\varphi_{l, k, m}+\sum_{i=1}^{k_{j}} \alpha_{l, k, i}\left(\varphi_{l, k, m}+g_{l, m}\left(\varphi_{l, k, i}\right)+\right. \\ l=1,2, \ldots, l_{*}\end{array}\right.$

Here are some examples of functions $g_{l, m}\left(\varphi_{1, k, m}, \ldots, \varphi_{l_{*}, k, m}\right)$ :

1) $g_{l, m}\left(\varphi_{1, k, m}, \ldots, \varphi_{l_{*}, k, m}\right)=\alpha_{1}^{2} \varphi_{1, k, m}^{2}+\ldots+\alpha_{l_{*}}^{2} \varphi_{l_{*}, k, m}^{2}-$ a case of positive interference; 
2) $g_{l, m}\left(\varphi_{1, k, m}, \ldots, \varphi_{l_{*}, k, m}\right)=\sum_{l=1}^{l=l_{*}}(-1)^{k+m+l} \alpha_{1}^{2} \varphi_{l, k, m}^{2}-\mathrm{a}$ case of alternating "negatives".

\subsection{GENERALIZED DIFFUSION-LIKE MODEL OF THE EDUCATIONAL SOCIAL AND COMMUNICATIVE ENVIRONMENT OF A CITY}

Fig. 1 shows an educational level of the educational social and communicative environment of a city, consisting of $n$ cliques. It is believed that the process of knowledge potential redistribution in each of these cliques occurs according to ratios described above.

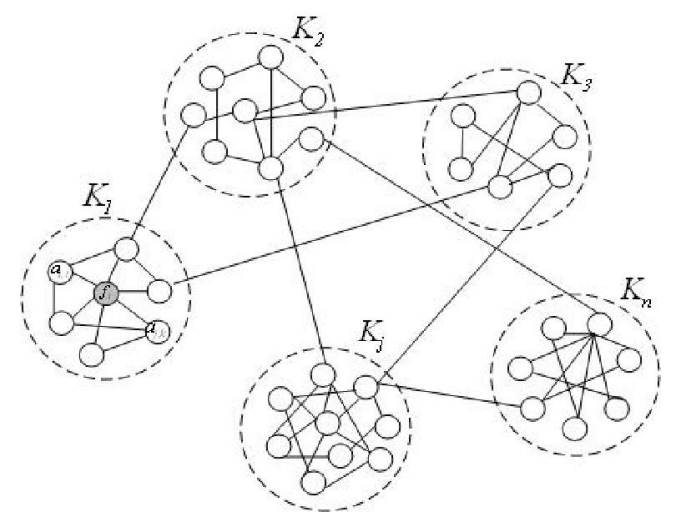

Fig. 1 - Schematic representation of clique of the educational social and communicative environment of a city within a specified educational level

$\varphi_{j, l, k, m}$ denotes knowledge potential of $l$ character of $k$ agent of $j$ clique at time $m$. It is a generalized model (8) in case of considering the interference not only between agents belonging to one social community (clique), agent groups of different cliques, as well as between cliques within a certain educational level in general:

$$
\left\{\begin{array}{l}
\varphi_{j, l, k . m+1}=\varphi_{j, l, k, m}+\sum_{i=1}^{k_{j}} \alpha_{j, l, k, i}\left(\varphi_{j, l, k, m}-\varphi_{j, l, k, i}\right)+ \\
+f_{j, l, m}+g_{j, l, m}\left(\varphi_{j, 1, k, m}, \ldots, \varphi_{j, l, k, k}\right)+ \\
+\varepsilon \sum_{j=1, q \neq j}^{n} \sum_{i=1}^{k_{j}} \alpha_{j, q, k, m}\left(\varphi_{j, l, k, m}-\varphi_{q, l, k, m}\right) \\
l=1,2, \ldots, l_{*}
\end{array}\right.
$$

where, $\varepsilon-$ a small parameter that characterizes the fact of small influences of situational cases in other cliques on knowledge potential distribution in this clique (i.e., it is offered too partial model that describes the natural situation of obtaining knowledge by agents in the social and communicative environment (school, group, team)).

For an easy presentation it is introduced a simplification: $\alpha=\alpha_{j}$ (capacity $\alpha$ is taken as one the same for all cliques and in most cases $\alpha=0$, so there is no link regarding to knowledge potential transfer between the agents of the clique and "left" number of the other clique).

\section{RESULTS}

The results of experimental studies of designed diffusion-like models of knowledge potential distribution between agents and the cases of changes in the intensity of knowledge potential of information source (teacher) within social and communicative clique in time are shown in these Figures, namely:

1) in Fig. 2 a) and in Fig. 2 b) the results of calculation of knowledge potential according to formulas (3-5) at different times are shown provided that salary of "extreme" agents within some educational social and communicative community (cliques) are zero, and the initial distribution is symmetric: $\quad \varphi_{1,0}=0, \quad \varphi_{2,0}=8, \quad \varphi_{3,0}=14$, $\varphi_{4,0}=18, \quad \varphi_{5,0}=20, \quad \varphi_{6,0}=20, \quad \varphi_{7,0}=18$, $\varphi_{8,0}=14, \varphi_{9,0}=8, \varphi_{10,0}=0$.

2) in Fig. 2 c) agent (teacher) passes on ("spent") his knowledge potential not only to outside agents (students) (which, according to classical diffusionlike model, in turn, spread the information to their "neighbors"), but at the same time to all the other agents within some cliques.

3) in Fig. 2 d) «teacher» increases knowledge potentials of individuals in different ways.

In Fig. 3 a) the calculation results are shown when the increase in "mathematical parameter" $\alpha$ leads to raise in the corresponding component of knowledge potential of a given agent within the specified social and communicative clique while maintaining the "linguistic component". And in Fig. 3 b) quite different results are predicted when a raise in "linguistic component" leads to a decrease in "mathematical component" (without affecting the "language"). 


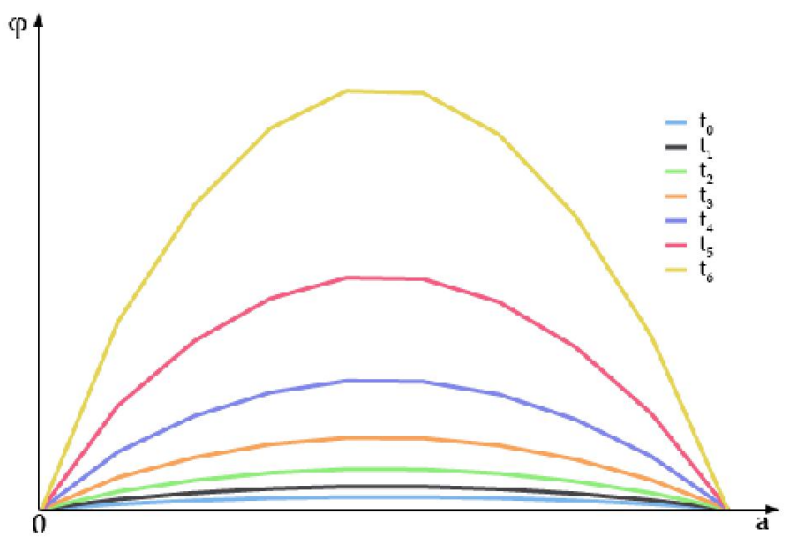

a)

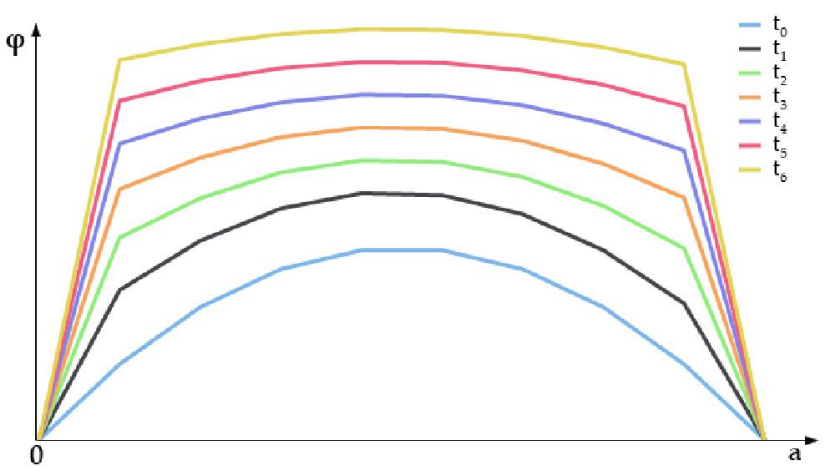

c)

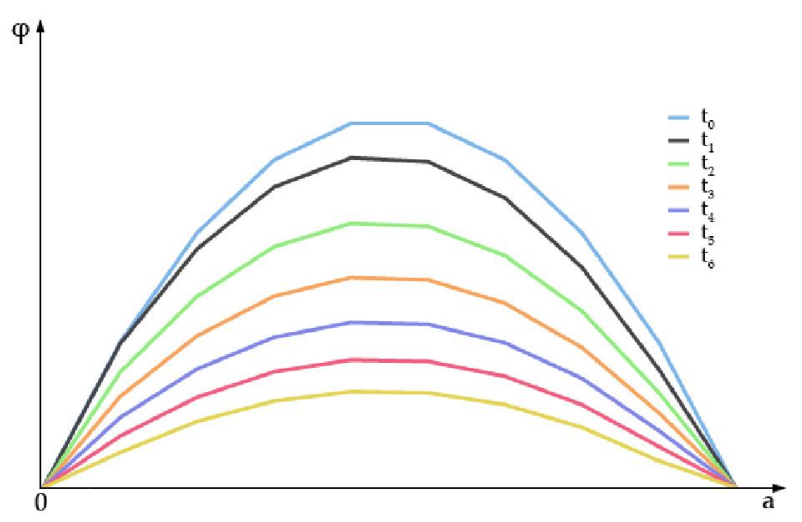

b)

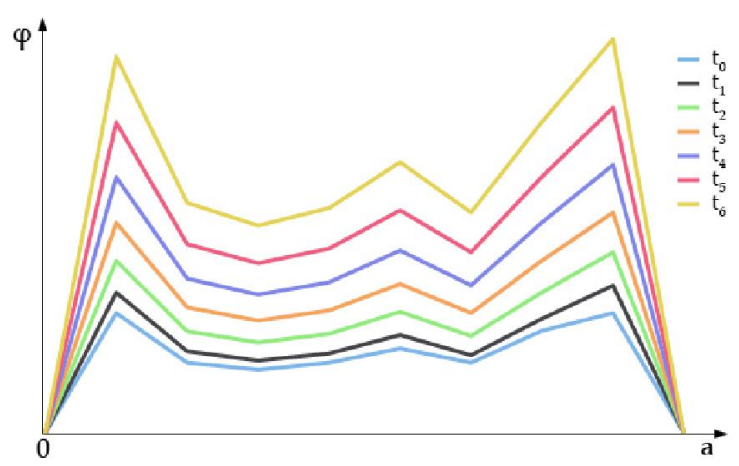

d)

Fig. 2 - The change of the knowledge potential intensity of information source (teacher) within the clique

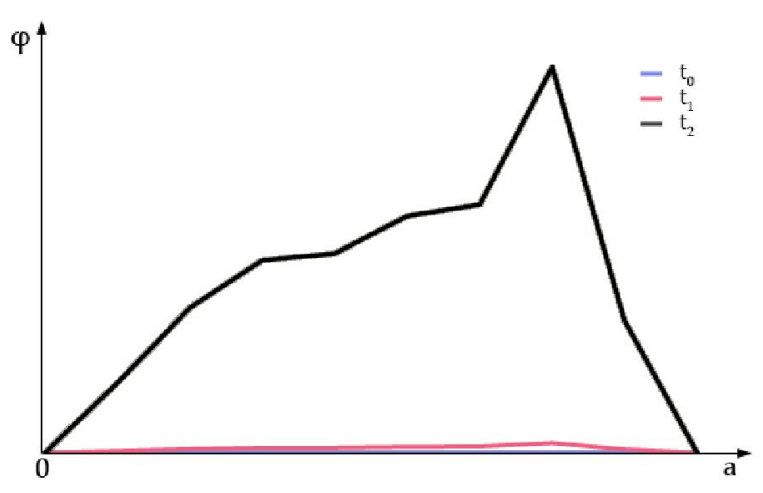

a)

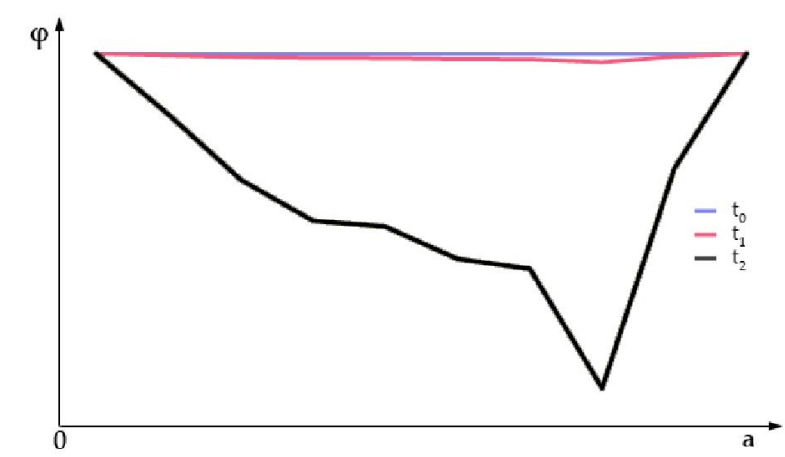

b)

Fig. 3 - Redistribution of two-component knowledge potential of agent

Certainly, it is necessary to conduct computer experiments on the basis of algorithms for solving the problems of multicomponent vectors of knowledge potentials for deeper description of situational states of agents (for example, teaching some classes). Also, it is important to solve the task of parameter identification [21] that requires a large number of experiments (in social space and time), as well as previous experience.

Moreover, the proposed diffusion-like model of the process of two-component knowledge potential spread can be used to make conclusions about preliminary feasibility to study agents in one or another clique (profile class) by means of psychological and educational experiments.

Fig. 4 schematically shows a situational condition of prior forecast that «recommends» this agent $a^{*}$ (at a stated time) to study in the mathematical classroom, and $a^{*}$ - in the language one. Moreover, under the proposed model, at a stated time we have good reasons to assert the correctness of the calculation in respect of the agent $a^{*}$ compared to the agent $a_{*}$. 


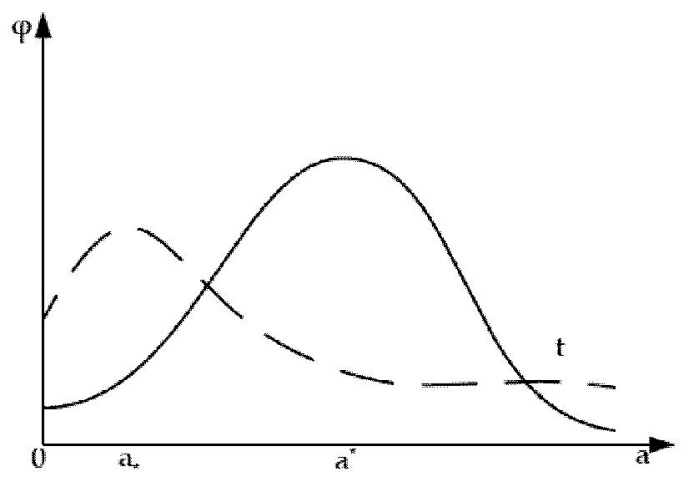

Fig. 4 - Situational conditions of distribution of "language" (solid line) and "mathematical" (dotted line) potential at a stated time

\section{CONCLUSIONS}

In the paper the diffusion-like models of information processes of two-component knowledge potential redistribution $\varphi$ in the educational social and communicative environment of a city were created. In particular, the attention is focused on the description (modeling) of redistribution processes of knowledge potential within a certain social and communicative community (clique), with wellformed external and internal relationship between the participants (agents) in educational and training processes.

Thus, firstly solutions to the task of modeling the interaction (interference) of knowledge potential components of different agents within certain cliques were proposed, and a multi-vector of knowledge potential (solving relevant problems for system of difference equations) was also considered.

Obviously, the characteristic of agents with various knowledge potentials (describing, for example, knowledge of mathematics, physics, literature, etc., the ability to make different kinds of decisions) provides the ability to specify data models, and the simulation of more realistic situational conditions that certainly has a great practical value.

\section{REFERENCES}

[1] M.P. Shyshkina, "Systems and means of knowledge modeling in a single information and educational space," Actual problems of psychology: Psychological theory and technology, Vol. 8, Issue 6, pp. 317-327, 2009. [in Ukrainian].

[2] M. Sağsan, B. Bingöl, "From learning organization to knowing organization: A practical view for building 'knowledge shrine' with four minarets," Contemporary Issues on Management and Organization Science, pp. 2344, 2010.
[3] M. Sağsan, T.D. Medeni, "Understanding "Knowledge management (KM) paradigms" from social media perspective: an empirical study on discussion group for KM at professional networking site," Organizational, Managerial, and Technological Dimensions, Vol. 1, pp. 738-755, 2011.

[4] M.S. Siavavko, O.M. Tretiak, "Indistinctly interval methods of a risk assessment and behavior entropy of social and economic system," International Scientific Journal on Economic Cybernetics, Issue 3-4, pp. 53-61, 2006. [in Ukrainian].

[5] F. Soliman, K. Spooner, "Strategies for implementing knowledge management: Role of human resource management", Journal of Knowledge Management, Vol. 4, Issue 4, pp. 337-345, 2000.

[6] D. Suslov, "Knowledge management at organization: main models," Creative Economy, Vol. 6, Issue 10, pp. 89-97, 2012.

[7] I. Nonaka, R. Toyama, "The theory of the knowledge creation firm: Subjectivity, objectivity, and synthesis," Industrial and Corporate Change, Vol. 14, Issue 3, pp. 419436, 2005.

[8] I. Nonaka, G. Krogh, S. Voelpel, "Organizational knowledge creation theory: Evolutionary paths and future advances," Organizational Studies, Vol. 27, Issue 8, pp. 1179-1208, 2006.

[9] N.F. Dobrynina, "Mathematical models of knowledge dissemination and management of the learning process of students", Fundamental research, Issue 7, pp. 7-9, 2009. [in Russian].

[10] V.B. Artemenko, "Hybrid of agent-based model of evaluating knowledge by the participants' of distance learning," Educational Technology and Society, Issue 2, pp. 423-434, 2011. [in Russian].

[11] A. Petrash, "Methods of information and mathematical modeling of educational process," in Proceedings of the International Conference on Innovative computer technologies in higher education, Lviv, Ukraine, October 18-20, 2011, pp. 128-132. [in Ukrainian].

[12] A.G. Dodonov, D.V. Lande, V.A. Dodonov, "Recognition of information operations: multiagent approach," in Proceedings of the International Scientific Conference "Open Semantic Technologies for Intelligent Systems", Minsk, Belarus, February 18-20, 2016, pp. 253259. [in Belarus].

[13] E.M. Rogers, Diffusion of Innovations, 5th ed., New York, 2003, 543 p.

[14] J. Kaminski, "Diffusion of innovation theory," Canadian Journal of Nursing Informatics, 
Vol. 6, Issue 2, 2011.

[15] T. Soffer, R. Nachmias, J. Ram, "Diffusion of web supported instruction in higher education the case of Tel-Aviv university," Educational Technology \& Society, Vol. 13, Issue 3, pp. 212-223, 2010.

[16] X. Gao, J. Guan, "Network model of knowledge diffusion," Scientometrics, Vol. 90, Issue 3, pp. 749-762, 2012.

[17] A.A. Malkova, "Application of the Bass model for identifying research strategies," Mathematical and Instrumental Methods of Economics, Vol. 6, Issue 115, pp. 141-145, 2014. [in Russian].

[18] Luttmer, Erzo G. J., "Four Models of Knowledge Diffusion and Growth," Working Papers 724, Federal Reserve Bank of Minneapolis, 2015, [Online]: https://www.minneapolisfed.org/research/wp/w p724.pdf.

[19] M. V. Nazaruk, V.V. Pasichnyk, "Modelling of urban educational environment as a profile social network," Information Technology and Computer Engineering, Vol. 3, Issue 28, pp. 42-47, 2013. [in Ukrainian].

[20] A.Y. Bomba, M.V. Nazaruk, N.E. Kunanets, V.V. Pasichnyk, "Generalized diffusion-liked model of information process of knowledge potential distribution," Radio Electronics, Computer Science, Control, Issue 3, pp. 63-70, 2015. [in Ukrainian].

[21] A.Y. Bomba, V.I. Havrylyik, A.P. Saphonyk, O.A. Phursachyk, Nonlinear Tasks of a Type Filtering-Convection-Diffusion Mass Transfer Under Conditions of Incomplete Data, Rivne, 2011, 275 p. [in Ukrainian].

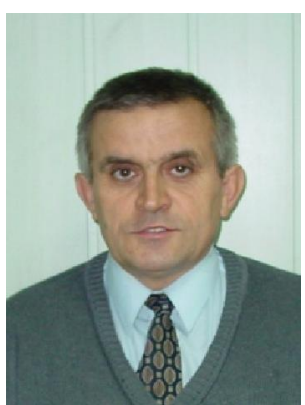

Andrii Y. Bomba is $P h D$, Candidate of Physical and Mathematical Sciences, Professor, the Head of Department of Computer Science and Applied Mathematics at Rivne State Humanitarian University. He graduated from Lviv State Franko University, specialty "Mathematics"; he was a postgraduate student at the Institute of Mathematics of the USSR and doctoral candidate at V. M. Glushkov Institute of Cybernetics of NAS of Ukraine. He is a specialist in the field of mathematical modeling and computational methods.

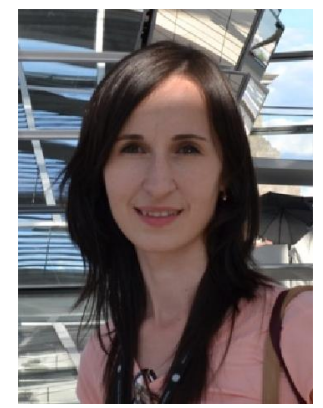

Mariia V. Nazaruk is a postgraduate student at the department of Information Systems and Networks at Lviv Polytechnic National University. She graduated from Rivne State Humanitarian University, specialty "Information science". Her fields of scientific activity are database and knowledge systems, distributed information and analytical systems, intelligent systems of decision support.

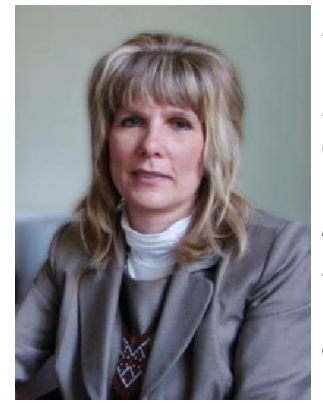

Nataliia E. Kunanets is PhD of Social Communications, Senior Fellow, Professor of the department of Information Systems and Networks, Deputy head of the department at Lviv Polytechnic National University.

She started to work in 1981 at Lviv Stefanyk National Science Library. Since 2009 she has been working at Lviv Polytechnic National University. In 2007 she defended her thesis at Vernadsky National Library of Ukraine. In 2013 she defended her doctoral thesis for the degree of Doctor of Science of Social Communications. She conducts research on problems of social and communicative technology in projects "Smart City", information support of scientific research carrying out on the platform of e-science and consolidation of information resources.

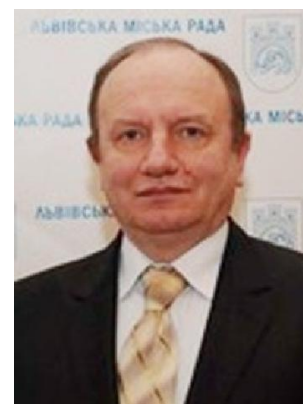

Volodymyr V. Pasichnyk is Professor, PhD, professor at the department of Information Systems and Networks, Institute of Computer Science and Information Technology, Lviv Polytechnic National University.

In 1978 he graduated with honour from the Faculty of Automation at Lviv Polytechnic

National University, the specialty "Automated control systems" and with a qualification of system engineer. In 1984 he defended his thesis for the degree of Candidate of physical and mathematical Sciences in Specialized Academic Council of V. M. Glushkov Institute of Cybernetics of NAS of Ukraine. In 1994 he defended his thesis for the degree of doctor of technical sciences, specialty "Theoretical foundations of computer science". Since the early 90 's, the scientific and professional interests are focused in the fields of creation and development of information systems for the real economy, production and non-production sphere. 